Prophylaxe

\title{
„Der sanfte Feinschliff“
}

Den extrem scharfen Knochenfräser H162ST, der seit Einführung im März 2015 spontan viele Fans gefunden hat, gibt es jetzt auf Wunsch der Kunden in der veredelten Version H162STZ. Der Fräser ist mit Zirkon-Nitrid beschichtet und in 3 Varianten erhältlich:

H162STZ.314.016

(Schaftart FG für den Einsatz im roten Winkelstück), H162STZ.204.016 (Schaftart Winkelstück) und H162STZ.104.016 (Schaftart Handstück). Alle diese Knochenfräser zeichnet die inno-

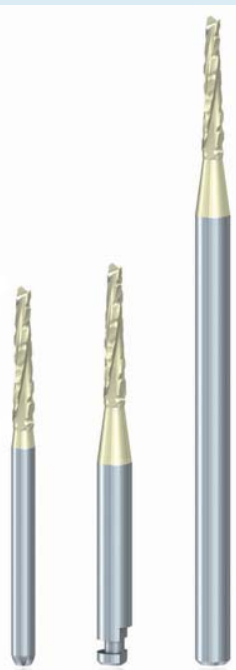
vative ST-Verzahnung aus. Sie bietet höchste Schnittschärfe, gutes Schneidverhalten und maximale Kontrolle z.B. bei Knochenschnitten im Rahmen einer Osteotomie, Osteoplastik, der Präparation von Knochen und Knochendeckeln. Wer mehr über das gesamte Chirurgie-Sortiment von Komet erfahren möchte, kann direkt online in der Chirurgie-Broschüre blättern oder diese über den persönlichen Komet-Fachberater anfordern

Nach einer Pressemitteilung der Komet Dental Gebr. Brasseler GmbH \& Co KG, Lemgo

www.kometdental.de 